J. Lake Sci. (湖泊科学), $2006, \mathbf{1 8}(4): 401-406$

http:// www. jlakes. org. E-mail: jlakes@ niglas. ac.cn

(c) 2006 by Journal of Lake Sciences

\title{
太湖西莒溪流域径流过程的模拟”
}

张奇, 李恒鹏, 徐力刚

(中国科学院南京地理与湖泊研究所,南京 210008)

摘 要: 西苔溪是太湖集水域的一个主要流域, 研究西苔溪流域径流过程及污染物产出对了解太湖水文水质变化以及开 展周围其它流域研究工作具有重要意义. 作为研究的第一步, 采用集总式模型 LASCAM 建立了西苔溪流域径流模型. 以 流域内 2 个水文观测站 $1968-1988$ 年日径流观测数据对模型作了率定. 率定效果满意, 模拟日、年径流量与观测值吻合 良好. 在流域资料不够充分的情况下,模型能获得较为理想的模拟效果,说明所采用的模型适用于数据不足区域. 模拟还 揭示, 西苕溪流域径流产生可能以饱和地面径流机制为主. 近河道浅层饱和土体的水位与降雨量相关性好, 呈现出明显 的日波动周期; 而深层地下水位呈年波动周期,在旱季和雨季, 水位呈明显的降落和上升趋势. 这些发现为进一步细化径 流模型以及建立污染物输移模型奠定了基础.

关键词: 地面径流; LASCAM; 西苕溪流域;太湖流域

\section{Surface runoff modeling for Xitiaoxi catchment, Taihu Basin}

ZHANG Qi, LI Hengpeng \& XU Ligang

( Nanjing Institute of Geography \& Limnology, Chinese Academy of Sciences, Nanjing 210008, P. R. China)

\begin{abstract}
Investigation on surface runoff and associated mass transport for Xitiaoxi catchment is of significant importance as it is one of the major catchments of Lake Taihu basin. Outcomes from this investigation help understand the dynamic changes of hydrology and water quality of lake Taihu, and are also useful in carrying out similar research work on other catchments of lake Taihu basin. As the first step, this paper presents the construction of a surface runoff model for Xitiaoxi catchment using a conceptual model, LASCAM. The model is well calibrated using daily runoff data from 1968 - 1988 from 2 monitoring stations within the catchment. The modeled daily and annual runoffs match well with the observed ones. The model indicates that saturation excess runoff is probably the dominant process for the catchment. Water storage in near-stream shallow saturated soil has high correlation with daily rainfall, while water storage changes in deep aquifers demonstrate an annual change period, showing a rising level for wet seasons and a declining level for dry seasons. The findings are helpful for further refining the runoff model and constructing nutrients transport model as the next step.
\end{abstract}

Keywords: Surface runoff; LASCAM; Xitiaoxi catchment; Taihu Basin

湖泊与其流域有着密切的水文联系, 流域径流是湖泊主要水源之一. 径流向湖泊汇聚过程中, 将流域 内的污染物带人湖体中,引起湖泊的污染. 特别是, 随着流域经济的快速发展, 流域土地利用类型和植被覆 盖都发生着变化. 这些变化改变了流域的径流特征, 同时, 也使更多的污染物(如水土流失、农田肥料、杀虫 剂) 向湖泊汇聚. 研究湖泊的污染, 制定防治污染措施时, 必须考虑流域内污染源的分布和污染物负荷的时 空变化,才能从源头上控制污染,并把污染物尽可能消除在人湖之前.

污染物以径流为输送载体, 在研究污染物输移时, 首先应对径流过程作细致的研究. 目前国际上已开 发了不同类型的模型 ${ }^{[1]}$, 这些模型几乎都同时包含了径流子模型和物质 (泥沙、氮、磷、盐等)输移子模型, 在定量模拟流域径流和物质输出对人类活动的响应中取得了良好的效果 ${ }^{[2-4]}$. 随着国内在流域监测方面

* 国家重点基础研究发展计划 (2002CB412310)、中国科学院百人计划项目共同资助. $2005-07$ - 25 收稿; $2005-10$ -24 收修改稿.张奇, 男, 1966 年生, 研究员; E-mail: qzhang@ niglas. ac. cn 
的重视, 流域数据日趋完善, 为开展流域模拟工作创造了条件.

本文目的是以西苕溪流域为研究对象,采用集总式模型建立其径流模型,对模型进行率定,并就模型的 适用性作探讨. 所建立的径流模型也为下一步开展污染物输移及产出计算奠定基础. 西苕溪流域是太湖 主要的水源之一, 研究西苕溪流域的径流过程及污染物产出, 有助于了解太湖水文水质变化, 并为建立太湖 地区其它流域的污染物输移模型提供可借鉴的技术方法.

\section{1 西莟溪流域概况}

西苕溪流域位于太湖上游地区的浙西水利分区,属山区水系,面积为 $2267 \mathrm{~km}^{2}$. 流域地势西南高, 东北 低, 依次从山地过渡为丘陵平原, 地面高程在 2-1578 $\mathrm{m}$ 之间. 西苕溪河长约 $143 \mathrm{~km}$, 源于天目山脉, 向北 流于湖州市杭长桥与东苕溪汇合人湖, 是太湖的重要水源之一. 流域内地带性土壤是红壤, 其次为黄壤, 耕 作土主要是水稻土. 土地利用以林地为主, 其次为耕地、居民地、草地和水体, 其中林地面积占 $62.4 \%$, 耕地 占 $29.7 \%$, 居民地占 $1.9 \%$ 。西莒溪流域属亚热带季风气候区, 多年平均降雨量为 $1465 \mathrm{~mm}$, 降雨主要集中 于 4-9 月,降雨量空间分布差异较大,年降雨量从西南山区的 $1800 \mathrm{~mm}$ 到东北区的 $1200 \mathrm{~mm}$ 呈逐渐递减. 该流域的蒸发强度呈较为明显的季节性变化, 夏季蒸发最大, 冬季蒸发最小. 蒸发强度从西南山区到东北 区呈增大趋势, 平均年蒸发量约为 $1200 \mathrm{~mm}^{[5]}$. 为了便于将径流模拟值与实测值进行比较, 本项研究选择 西苕溪下游范家村站所在位置为流域出口, 模拟的流域面积为 $1934 \mathrm{~km}^{2}$.

\section{2 径流模型}

\section{1 模型的选择}

分析比较目前国际上常用的模型后, 选择 LASCAM (Large Scale Catchment Model) ${ }^{[6]}$ 模拟西苕溪径流， 主要基于以下几个原因的考虑:

(1) 这是一个概念化集总模型,计算单元为基于河系和地形高程剖分的子流域,所需数据相对于分辨 率更高的分布式模型少,符合西苕溪流域目前所拥有的数据; (2) 该模型在设计上考虑大尺度流域的水文 特点, 适合于类似西苕溪流域尺度的流域; (3) 该模型包含了径流、泥沙、氮、磷、盐分的模拟模块, 可以同时 对这些物质作模拟,也可以将某模块单独运算, 比如先进行径流的模拟,再作物质产出的模拟,符合模型建 立的一般步骤及西苕溪的实际情况; (4) 该模型的核心是定义了 3 个储水区来描述流域内水量的空间分 布: 河溪附近表层饱和土 (A 区) 、深层地下水区 ( B 区) 以及介于两者之间的非饱和区 ( F 区). 这 3 个储水 区之间的水量交换代表真实条件下水流的运动和水量在流域内的分布. 这个概念化思想简单明了, 又具有 合理的物理基础, 符合大多数流域的水文特征; (5) 该模型包含一个参数自动优化程序, 避免了人工试探参 数带来的繁琐和盲目,便于作较长时间系列的参数率定.

流域物质输移的模拟中,径流过程的模拟是关键,其结构决定了模型的复杂程度和模型的仿真效果, 同 时又决定了相应物质输移的计算方法. LASCAM 包含的水文过程有:

(1) 降雨的植被拦截:植被叶面对降雨有拦截作用,降雨去除植被拦截的水量后得到达到地面的净降 雨量; (2) 地面径流: 到达地面的降雨转化为地面径流的过程, 考虑了超渗地面径流和饱和地面径流两种机 制; (3) 地下径流: 人渗地下的水量在 3 个储水区 $\mathrm{A} 、 \mathrm{~B} 、 \mathrm{~F}$ 之间的分配和交换,基流通过 $\mathrm{A}$ 储水区实现,储水 区 $\mathrm{B}$ 和 $\mathrm{F}$ 都不直接与河道发生水量交换; (4) 河道径流: 地面径流和地下基流进人河道的水量在河道中向 下游运动,最终到达流域出口断面; (5) 蒸散发: 植被拦截水量及 $A 、 B 、 F$ 储水区的水量都可以通过蒸散发损 失到大气中, 这些蒸散发分量的总和构成模型总蒸散发量. LASCAM 在模拟流域径流时, 首先将流域剖分为 若干个子流域. 以日为计算时间步长, 对每个子流域作水量平衡计算, 再依据各子流域在河网中的上下游 关系, 将水量汇人河网中,最终汇集到流域的出口断面. 模型的更多细节可以参阅文献 ${ }^{[6,7]}$.

\section{2 模型的建立}

按 LASCAM 子流域剖分要求和西苕溪流域地形水系数据,整个流域剖分为 47 个子流域如图 1 示. 这 些子流域通过河网连接成上下游关系,这种关系通过一定的数据格式输人模型中, 实现水量在各子流域间 的传递. 


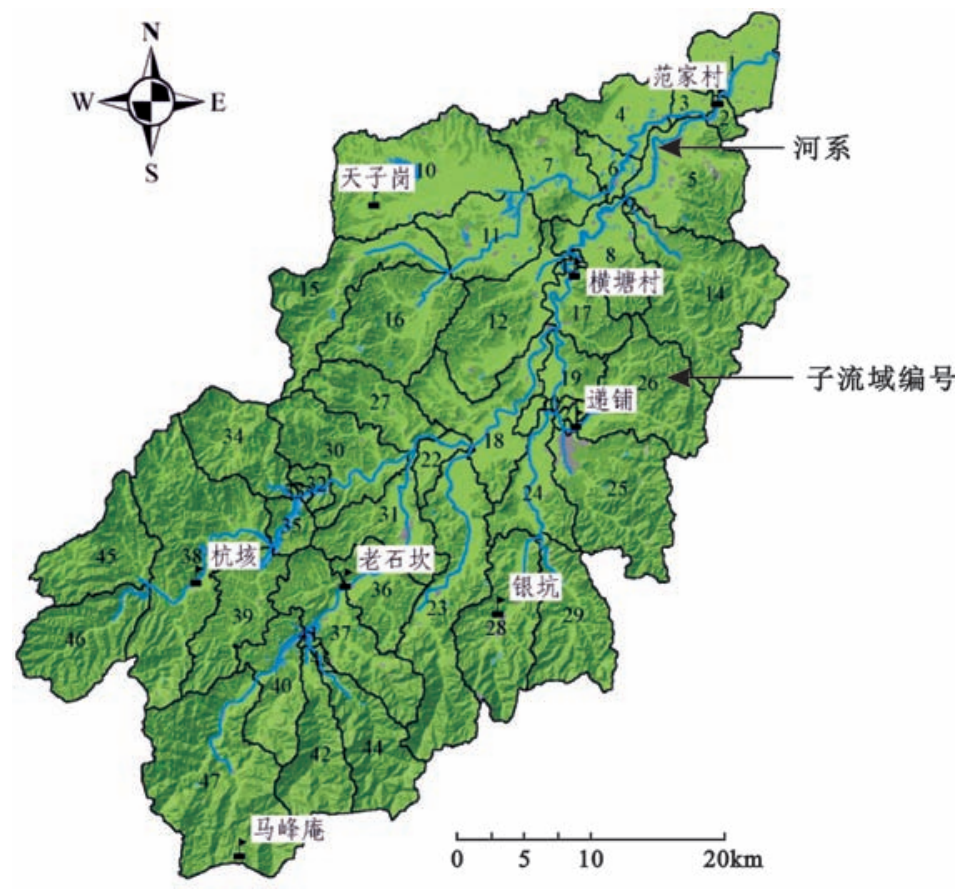

图 1 西苔溪流域及子流域剖分

Fig. 1 Subcatchment discretization of Xitiaoxi catchment

模型需要的其它输人条件有土地覆盖信息、各子流域多年平均年降雨量、年蒸发量和日降雨量.土地 覆盖信息主要包括叶面指数 ( LAI) 和城镇用地. 西苕溪流域尚没有开展叶面指数的观测与计算, 没有直接 的数据可以使用. 在本次研究中, 叶面指数由下式估算:

$$
L A I=L A I_{\max } F O R / 100+L A I_{\text {min }}(1-F O R / 100)
$$

式中, $L A I$ 为某子流域年平均叶面指数; $L A I_{\text {max }} 、 L A I_{\text {min }}$ 分别为某子流域最大、最小年平均叶面指数相对值; $F O R$ 为子流域中森林所占的面积 $(\%)$;

显然,式 (1) 基于这样的假定: 叶面指数与森林面积成线性关系; 当森林面积占子流域面积 $100 \%$ 时, 叶 面指数为 $L A I_{\text {max }}$; 当森林面积占子流域面积 $0 \%$ 时, 叶面指数为 $L A I_{\text {min }}$. 这样算得的叶面指数基本能反映各 子流域间的相对情况, 尽管计算值与实际真实值可能存在误差, 但这个误差在模型的率定中能得到补偿. LASCAM 不特别要求输人模型的叶面指数与真实值吻合, 只要求各子流域间的相对情况得到反映即可 ${ }^{[6]}$. 式 (1) 的系数 $L A I_{\text {max }}$ 和 $L A I_{\text {min }}$ 在模型率定中作了调试, 发现其取值分别为 3.5 和 1.5 时较为合适. 叶面指数 显然还与季节有关, 这种年内的季节性变化通过赋予每月权重系数加以实现,算法如式 (2)示:

$$
L A I_{M}=C_{m} L A I
$$

式中, $L A I_{m}$ 为月份 $m$ 的叶面指数; $C_{m}$ 为月份 $m$ 的权重系数.

由于目前尚缺乏研究区的 LAI 实测参数,而 LAI 与植被指数 (NDVI) 都是代表流域地表覆被的生态参 数, LAI 的月变化在一定程度上可以通过 NDVI 来反映, 而且 LASCAM 模型输人值不需要与真实值吻合, 只 要求反映相对情况, 故本项研究采用 NDVI 的月变化来代表 LAI 的月变化系数. NDVI 数据采用 USGS_LP DAAC 的 $1 \mathrm{~km}$ 格网数据, 对各月数据进行投影转换, 使其与研究区其它数据投影一致, 通过叠加分析统计 研究区各月的 NDVI 数值. 由于同一季节的植被指数变化不明显, 为简便, 在同季节内将 $C_{m}$ 设为常数, 采用 季节内各月平均数来表示. $C_{m}$ 数值变化幅度为从冬季的 0.5 到夏季的 1.5 . 流域内城镇分布根据土地利用 资料获得. 城镇所在地尽管由不透水的道路和建筑物以及透水的草地组成, 但在模型中, 城镇地被处理为 不透水地面, 不再区分透水的草地. 
日降雨条件由流域内的 8 个降雨观测站获得, 它们是杭垓、马峰庵、老石坎、银坑、递铺、横塘村、天子岗 和范家村, 空间分布如图 1 示. 除了日降雨量, 模型还需要各子流域的多年平均年降雨量, 用于在模型开始 运算时调整储水区 A、B、F 的初始水位. 子流域年降雨量根据 $1958-1988$ 年降雨观测数据插值获得. 在定 义蒸发条件时, 模型需要两个条件:一是年蒸发量;二是描述蒸发量年内分布的函数. 年蒸发量根据观测数 据和已发表数据获得. 模型要求各子流域的蒸发量数值能大致反映流域蒸发强度空间变化的梯度, 而对其 绝对数值的正确性没有严格要求. 因为很难得到每个子流域实际观测的日蒸发量,模型以年蒸发量为基 础,通过正弦函数计算出各子流域的日蒸发量. 正弦函数可以通过代表性观测年的数据拟合获得或者根据 该地区蒸发量年内分布确定. 对横塘村日蒸发量观测数据 (由 $20 \mathrm{~cm}$ 口径蒸发血观测获得) 分析得出的正弦 函数为:

$$
f=A \cdot \operatorname{Sin}(2 \pi / D \cdot t-2 \pi / D \cdot \phi)
$$

其中, $A$ 为 $0.63 ; D$ 为 1 年的天数; $\phi$ 为 $295(\mathrm{~d}) ; t$ 为时间 $(\mathrm{d})$; 由式 $(3)$ 得日蒸发量为:

$$
e=(1-f) \cdot E / D
$$

其中, $e$ 为日蒸发量 $(\mathrm{mm}) ; E$ 为年蒸发量 $(\mathrm{mm})$;

取横塘村 1988 年蒸发观测为例,该年度年蒸发量 $E$ 为 $916 \mathrm{~mm}, D$ 为 $366 \mathrm{~d}$, 由式(3)、(4) 计算得到的日 蒸发量与实际观测值的比较如图 2 示.

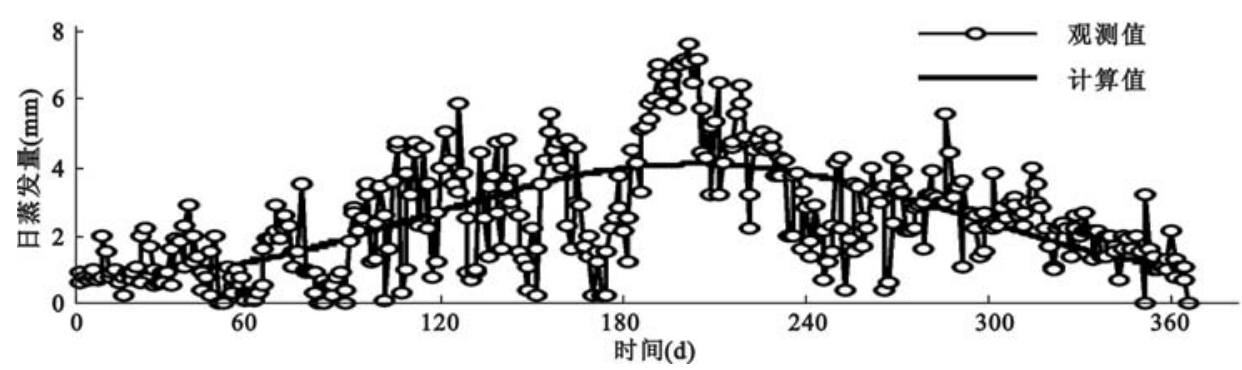

图 2 横塘村 1988 年日蒸发量观测值与模型概化值

Fig. 2 Comparison of calculated and observed daily evaporation of 1988 at Hengtangcun

\section{3 模型的率定}

模型率定是模型建设中重要的工作, 率定主要有 “试错法” 和“自动参数估算法” ${ }^{[8]}$, 两种方法在实践中 都有应用, 有时两种方法的结合使用可以取得最佳的效果. LASCAM 包含了自动优化程序, 可以有系统地 调整参数使模型计算值 (径流量) “最佳” 逼近观测值. 因 LASCAM 为概念化集总模型, 除极少数参数, 如河 流流速, 具有真实物理意义外, 大多数参数为无物理意义的经验参数, 这些参数只有在模型率定中加以确 定. 本次率定的参数主要有储水区 $A 、 B 、 F$ 的初始储水量和控制各储水区水量储存和相互传递的参数 18 个, 定义河流流速的参数 3 个, 共计 21 个. 选择横塘村和范家村两站点 $1968-1988$ 年的径流量观测值作为 模型率定的目标值. 这两个站具有较长系列的径流观测, 控制面积分别占整个流域面积的 $67 \%$ 和 $98 \%$, 能 较理想地反映整个流域的径流特征. 其它一些水文站点因靠近水库下游, 观测值受水库影响较大而不适用 于模型的率定.

图 3 和 4 表示率定时段内模型计算值与观测值 (已换算成径流深度) 的比较,总体上说, 日径流量和年 径流量模拟值与观测值都有良好的吻合. 如果以效率系数 $e\left(e=1-V_{r} / V_{o}, V_{r}\right.$ 为观测值与模拟值的差的方 差, $V_{o}$ 为观测值的方差, $e$ 的范围为 1 至 $-\infty$ 分别表示 “最优” 至 “最差” 的吻合) 表示模拟值与观测值的吻 合程度, 则横塘村和范家村两站点的效率系数分别为 0.844 和 0.882 . 从图 3 知, 模拟的径流峰值有小于观 测值的趋势, 这可能由于对植被覆盖条件的近似引起,也可能由模型本身对真实世界的近似引起. 图 3(c) 表 示整个流域出口断面处 (1 号子流域) 的径流量, 该子流域没有观测值作比较,但应该与 2 号子流域 (范家村站 点) 的径流量较为接近. 在模型率定中发现, 西苕溪流域地面径流的产生可能以饱和地面径流机制为主, 即在 

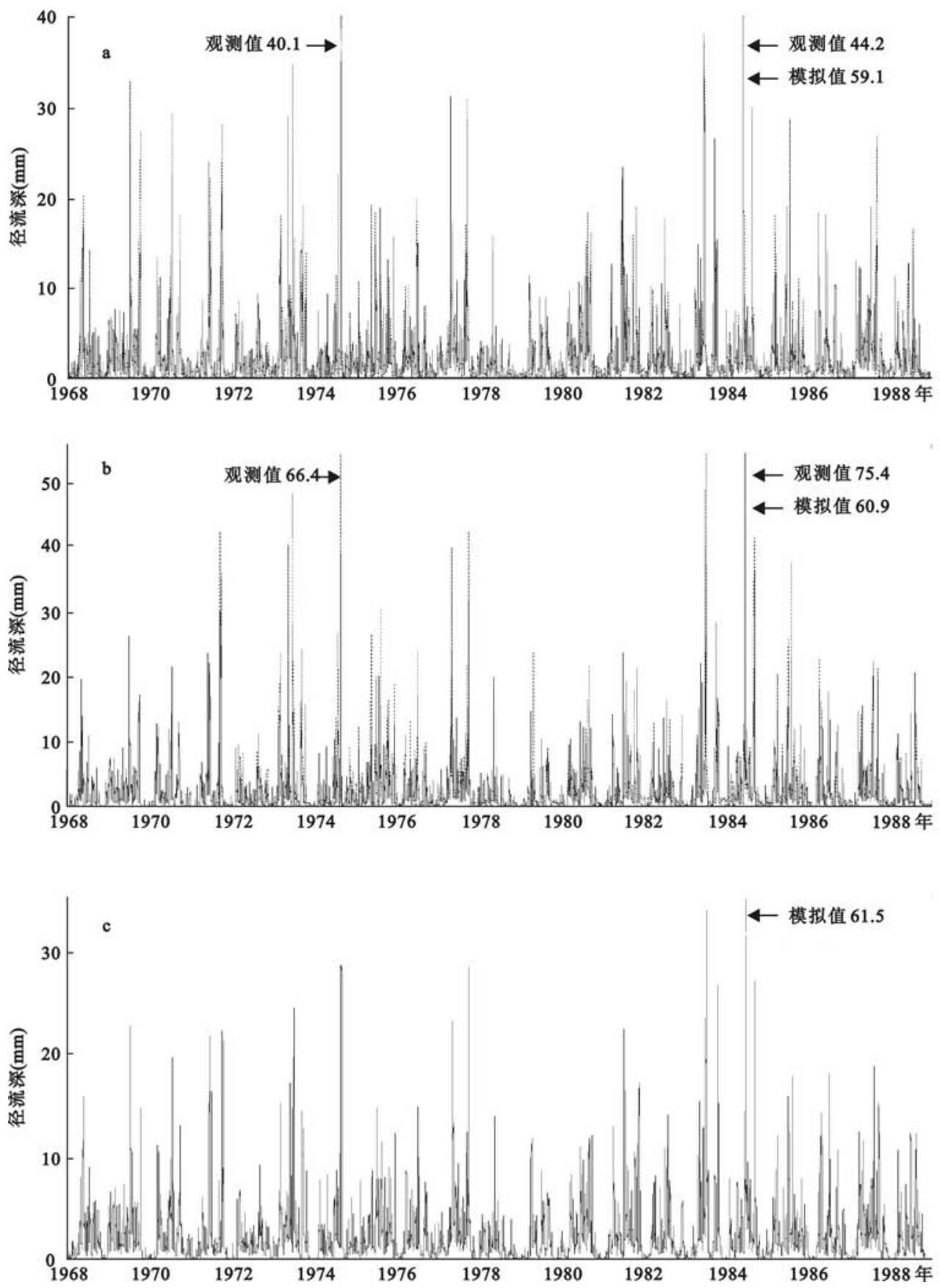

图 3 日径流量模拟值与观测值的比较 ( $\cdots \cdots$. 为观测值;一一实线为模拟值) ( $\mathrm{a}$ : 范家村 $; \mathrm{b}$ : 横塘村; $\mathrm{c}$ : 流域出口断面径流模拟值)

Fig. 3 Comparison of modeled and observed daily runoff (dashed line for observation; solid line for modeled results) 河道附近,由于地下水位较浅,降雨首先使表层包气带饱和,随后产生地面径流汇人河道; 在距离河道较远的 地方,降雨人渗地下,再以基流形式汇人河道. 这得到地下水位观测的初步证实, 比如, 在靠近河道处,地下水 埋深较浅,为 $0.5-2.0 \mathrm{~m}$. 由模型输出的储水区 $\mathrm{A} 、 \mathrm{~B} 、 \mathrm{~F}$ 的储水量变化数据分析,西苕溪的径流特征还表现在 
储水区 $\mathrm{A}$ (表层饱和土) 的水量呈明显的日波动周期, 与日降雨量相关明显; 而储水区 $\mathrm{B}$ (深层地下水) 的水量 呈年波动周期, 在每年的汛期, 储水量增加; 在旱季, 储水量减少. 储水区 $\mathrm{F}$ (介于 $\mathrm{A}$ 和 $\mathrm{B}$ 间的非饱和区) 在模 型中作用不明显. 这些发现有助于更确切地概化水文模型以及建立恰当的污染物输移模型.
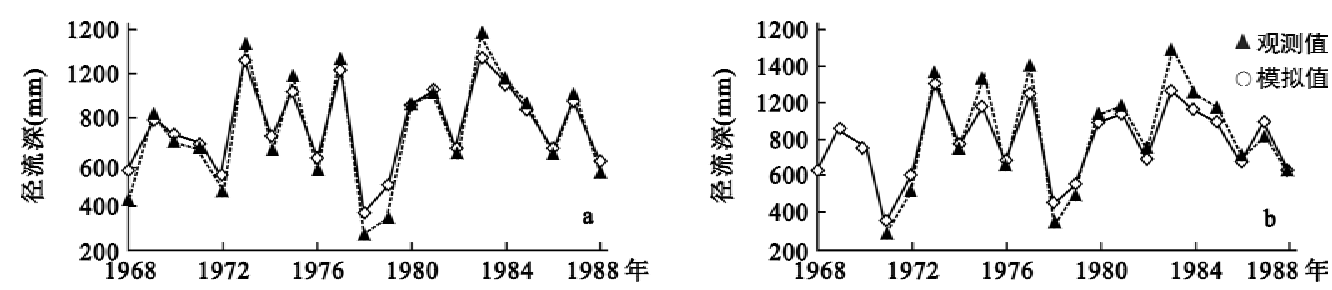

图 4 年径流量模拟值与观测值的比较 ( $\mathrm{a}$ :范家村; $\mathrm{b}$ : 横塘村)

Fig. 4 Comparison of modeled and observed annual runoff (triangles for observation; circles for modeled results)

本次模型率定的时间段为 21 年, 该时间长度已基本包含了流域的特征水文条件,检验了模型在各水文 条件下的模拟能力, 所以, 本文未对模型作另外时段的验证. 在今后更多数据资料具备的基础上, 可以对模 型作进一步的验证.

\section{3 结论}

(1) 模型率定效果良好,能较为满意地重现率定时段内的径流量. 模拟日、年径流量都与观测值吻合良 好, 模拟值呈现略高于低径流观测值而略低于高径流观测值的趋势; (2) 尽管缺乏足够的现场数据, 比如, 叶面指数、蒸发量、降雨量的空间分布都没有足够的实测数据,模型仍能满意地模拟径流规律, 表明该模型 对实际现场数据要求不高, 能在模型率定过程中, 通过调整某些参数来弥补现场数据的不确定性, 较适合缺 乏现场数据的流域; (3) 西苕溪流域径流产生可能以饱和地面径流机制为主, 超渗地面径流为辅. 河道附近 浅层饱和土体的水位与降雨量相关性好, 呈明显的日波动周期; 而深层地下水位呈年内季节性波动; (4)径 流模型的成功建立验证了模型的适用性, 为下一步污染物输移的模拟奠定了基础.

致谢 澳大利亚 CSIRO 土地与水研究所的 Neil Viney 博士提供了 LASCAM 计算程序, 并在模型的使用过程 中给予了诸多帮助;刘佳、徐金涛做了数据准备工作,在此一并致谢.

\section{4 参考文献}

[1] Merritt W S, Letcher R A, Jakeman A J. A review of erosion and sediment transport models. Environmental Modelling \& Software, 2003, 18: $761-799$.

[2] Johnson M S, Coon W F, Mehta V K, et al. Application of two hydrologic models with different runoff mechanisms to a hillslope dominated watershed in the northeastern US: a comparison of HSPF and SMR. Journal of Hydrology, 2003, 284 : 57 - 76.

[3] Jayatilaka C J, Storm B, Mudgway L B. Simulation of water flow on irrigation bay scale with MIKE-SHE. Journal of Hydrology, 1998, 208: 108 - 130.

[4] Viney N R, Sivapalan M. Modelling catchment processes in the Swan-Avon river basin. Hydrological Processes, 2001, 15: 2671 - 2685.

[5] 中国科学院南京地理与湖泊研究所, 水利部太湖流域管理局. 太湖流域自然资源地图集. 北京: 科 学出版社, 1991: $11-19$.

[6] Viney N R, Sivapalan M. LASCAM: The large scale catchment model, User Manual, version 2. Centre for Water Research, University of Western Australia, 2000.

[7] Sivapalan M, Ruprecht J K, Viney N R. Water and salt balance modeling to predict the effects of land-use changes in forested catchments. 1. Small catchment water balance model. Hydrological Processes, 1996, 10: $393-411$.

[8] 张 奇. 数值模型在地下水管理中的应用. 水文地质工程地质, 2003, 30(6) : 72 - 79 . 